macht gelangt, wohl die Errungenschaften der vorgefundenen überlegenen Kultur sich dienstbar machen, aber doch ihr eigenes Wesen und ihre eigene Ueberlieferung zur Geltung und mit den technischen Mitteln, die sie vorfinden, zu schneller Entfaltung bringen, ohne sich in die Schranken zu fügen, die ihren Vorbesitzern gezogen waren.

Neuburg a. Donau, Ende Januar 1907. Otto Weber.

\section{Südarabisches III.}

Von Martin Hartmann.

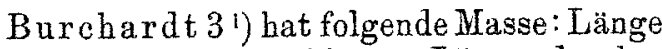
des ganzen Steines $106 \mathrm{~cm}$, Länge des beschriebenen Teiles $95 \mathrm{~cm}$, Breite des Steines $21 \mathrm{~cm}$, Höhe der Buchstaben $3 \mathrm{~cm}$. Den Stein fand Burchardt in dem von ihm in Sanaa Januar 1907 bewohnten Hause am Tore des Hinterhofes eingemauert. $\operatorname{Er}$ ist gebrochen und das Stück mit Z. 19-24 schliesst nicht genau an das Oberstück an ${ }^{2}$ ). Dieses ist links defekt, wenn nicht der Rand überkalkt ist, das Unterstück ist rechts und links vollständig, nur $7.21-24$ sind rechts beschädigt. Die Inschrift lautet nach der Foto, eingegangen den 15. März 1907 mit Brief d. d. Sanaa 15. Febr. 07, so:

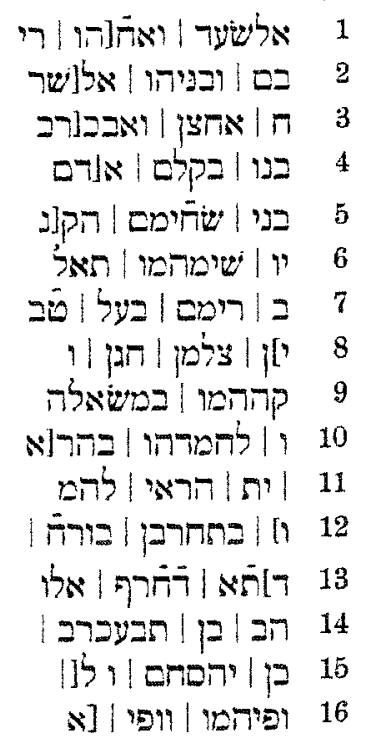

1) Ich zäble Burchardt $1=$ Lidzbaraki, Ephemeris 1,221 f, Burchardt $2=$ Lidzb., Eph. 2,93 ff.

2) Der Bruch war wohl schon vor der Einmauerung erfolgt, und die Bemühung, mit der man die Stilcke zusammengesetzt hat, lässt vermuten, dass ein solcher Stein aus der vorislamischen Zeit des Landes als eine Art Talisman fur das Haus gilt.

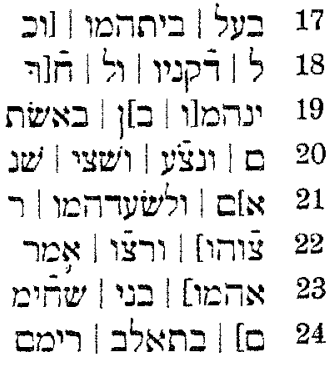

Zur Textgestalt: Die Zeilen haben zwischen 12 und 14 Zeichen. Die Ergänzungen sind überall sicher; nur in Z. 11 befremdet das Vacuum am Ende, das dadurch entsteht, dass das I von inh' auf $Z .12$ gesetzt isti). Eine Anomalie zeigt חงר: dem ת' Z. 11 Anfang geht deatlich der Trenner vorher, der da nichts zu suchen hat; er ist wohl für $N$ verschrieben, für das am Ende von Z. 10 nicht recht Platz ist. - Zu der Ergänzung [[] 20 Z. $7 \mathrm{f}$. siehe den Komm. zur Stelle. $\mathrm{Zu}$ beachten ist die Schreibung des $\overline{0}$ : sie unterscheidet sich deutlich von der des s: dieses hat überall, wo es hier vorkommt (j)א, jלs, zogen bis unten, das 0 hat den Knopf mit Strich aufsitzend. Ich vermute, dass mehrfach die anomale Schreibung $y$ statt $\dot{\theta}$ in den Halévy-Inschriften (z. B. רצn statt 7וōn $504,6)$ sich aus einem Uebersehen der kleinen Differenz durch den Kopisten erklärt.

Kommentar: 1. אלע: Wohl zu denken als $i \bar{\imath} s a^{6} d$ nein Grott ist Glück" oder $i l \bar{\imath}$ sacad "mein "Gott hat glücklich gemacht" ${ }^{2}$ ).

1) Die Zerreissung gerade beim , scheint besonders beliebt, s. hier Z. 9/10. 11/12. O. M. 6, 7/8.

$\left.{ }^{2}\right)$ In Ergänznng und Berichtigung meines "Zur Inschrift von Namära" OLZ. IX (1906) Sp. 573 ff. bemerke ich, dass ich zwar an der Dentung der letzten

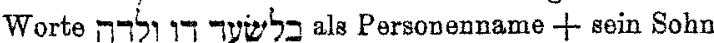
testhalte, dass ich aber in dem ersten Teile des Namens nicht mehr $b \bar{l} l$ (bell) sehe, sondern $b i^{3} i l$ (vgl. Surahbil, das doch wohl $=\check{s u r a h}$ bo"il); dass das $\$$ ausgefallen, erklärt sich durch dio Zusammenwerfung mit dem $b \bar{l} l(b \bar{e} l)$, das die Araber ron den aramäisch oprechenden Syrern hörten; auch in der Auffassung des Namens mag das Ursprüngliche durch die Häufigkeit des bal in den gehörten Namen der Fremden ausgelöscht worden sein. Das Zusammenwirken mehrerer Faktoren zar Erklärung einer sprachlichen Erscheinung hier heranzuziehen erscheint unbedenklich. Durch Ergänzung eines $s a d$ oder srh oder eines ähnlichen Wortes werden anch zu orklären sein die so hänfigen Namen mit $ב$ in den safatenischen Inschriften, aus deren nächster Nachbarschaft ja die Namära-Inschrift stammt (s. uber diese Namen Lidzbarski, Ephemeris 2, 39f). - Zu sa ad "hat beglickt" $v$ gl. die stehende Formel in und die Ausführungen Vollers, Vollssprache und 
$\mathrm{Zu} i \bar{i}$ als erster Namenbestandteil ist heranzuziehen אלקום Hal. 389,3. 6, d.i. Diqawim oder Ilĩqauwäm im Sinne von "Gott ist stetig"

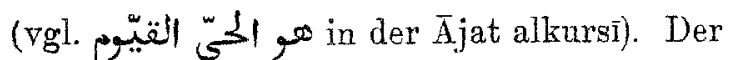
Name ist wichtig, weil er in dem oft besprochenen שיעאיקים einer nabatäischen Inschrift und der palmyrenischen Inschrift von 132 n. Chr. zu suchen ist $\left.{ }^{1}\right)$. Darin das nordar. القو zu sehen, ist zwar bequem, aber nicht eben empfehlenswert. Dass in den aramäischen Kreis ein sitdarabischer Gott eingedrungen, hat freilich auch Schwierigkeiten, zumal sis allein Personenname ist. Es ist aber hier mit w' verbunden; auch schliesst das Vorkommen als $\mathrm{PN}$ in Hal. 389 den Gebrauch als Gottesname in den aramäischen Inschriften nicht aus. Besonders ist zu beachten, dass der Setzer der palmyrenischen Inschrift Reiter war im Kastell und im Lager von 'Ana und dass 'Ana zur Einflusssphäre von Hira gehört, wo auch wohl schon vor den Lachmiden südarabische Araber die Herrschaft übten (dann gewinnen wir ein zweites Beispiel südarabischen Einflusses in Babylonien, wie eines schon in der Warka-Inschrift vorliegt). Die palmyrenischen Offiziere, die längere Zeit in südarabischer Umgebung in Garnison lageu, gerieten in deren Vorstellungswelt. Damit hängt der Synkretismus zusammen, der in ganz Vorderasien so seltsame Bildungen schuf. Ihm ist auch das Vorkommen im nabatäischen

Schriftsprache S. $108 \mathrm{ff}$, die durch das südarabische dew $=$ dew gestützt werden.

1) Die Literatur über die Inschriften und eigene Behandlung gab Lidzbarski, Eph. 1,332 und 345 .

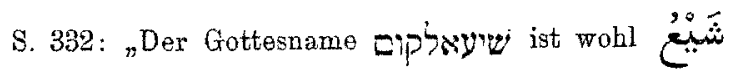
"der Beistand der Leute", vielleicht speziell ein Karawanengott". Gibt man dem $x_{N}$ die Bedentung des nordarab. Artikels, so wird sich für Dip

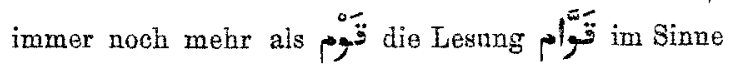
von قَيَّون empfehlen, und wir hätten dann für das

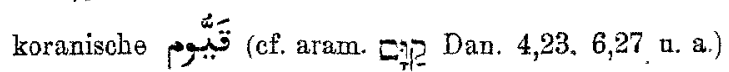
ein Präcedens im benachbarten Kreise. Wie aber nur Beiwort ist, so mag anch hier der Hauptname des Gottes in dem yw gesehen werden. Der Zusammenstellung mit عُ (bei Lesung šjuja ) stehen so grosse Bedenken entgegen, dass ich sie hier mit aller Reserve vorlege (uber die ganze Suwa $\tilde{a}^{\bar{k}}$-Frage an anderm Ort).
Kreise zu verdanken. - 4. בנו בקלם: dieser Familienname scheint sich in den Inschriften sonst nicht $z$ a finden. TA gibt $(7,232)$ : „banū bäqil eine Sippe (haij) von Al'azd; man heisst sie auch baql1): (Komm.) in der Gamhara heisst es wörtlich: 'im Stamme Al'azd gibt es eine Sippe, die baql genannt wird; das sind die ban̄ bäqil" "vgl. Ibn Doraid 297). Es ist keineswegs gesagt, ja sogar böchst unwahrscheinlich, dass die Bauernfamilie Bāqil oder Baql, die unsere Inschrift gesetzt hat, etwas mit jenen bann bāqil zu tun hat. Ihre Glieder Ilīsa'd und Ilišarah und Söhne nennen sich hier "Leute (Pächter, Hörige) der Banū Suchaim“."Ueber addam als Plural zu 'abd und seine wirtschaftliche Wertung s. mein "Die Arabische Frage"

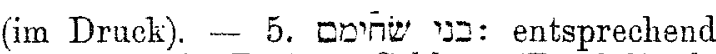
dem ădam in Z. 4 am Sehluss (Z. 22 f.) als "Herren" (amră $\left.\vec{a}^{\prime}\right)$ der Banū Bāqil genannt, also eine Adelssippe, d. h. wahrscheinlich Feudalherren mit Territorialgewalt. Es wird sich nie mehr mit Sicherbeit ausmachen lassen, welche Sippen des jemenischen Adels eine grössere Selbständigkeit als Territorialherren besassen. In der älteren Zeit (Minäer-Zeit) scheint die Bezeichnung mit 7 , PI. אהל kennzeichnend zu sein; in der späteren finden wir ein so gewaltiges Geschlecht, wie das der Banū Hamdān (Banū Bata') nur mit banü (das לNs scheint in Verbindung mit hamdan (bata) nicht vorzukommen). Die Adelsfamilie Suchaim begegnet noch Hal. 4,3 (lies $w / p$ ), 63,8 (desgl.). 87,2. 140,2. In OM 22,1 scheinen die Heransgeber שür den SippenNamen zu halten; an dieser Stelle ist aber durchaus ein Personenname zu erwarten; dass es בנו gibt, spricht gerade dafür, dass Suchaim auch als Einzelname vorkommt, wie Paul, Martin, Wilhelm zugleich Personen- und Familien-Namen sind 2 ). -7 .

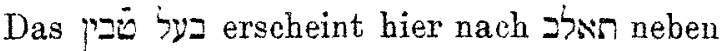
תאלב ערי תרער Glaser 869,1 (= Berliner Mus. 2683)

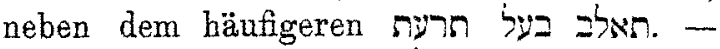
10 f. הרצי | wendung des Stammes int scheinen sich

1) בp als Appellatirum ("Gemöse") scheint in den Inschriften nicht belegt; doch ist $x u$ ihm $3 p 2$ Hal. 151,9 zu stellen: „er (Mutabnatjän) liess Frúchte grünen 113 Feddän".

3) So anch Hizfir sowohl Personenname wie Hal. 650,1 als auch Sippenname (mit 7) wie Hal. 615,17 
Parallelen in den Inschriften nicht zu finden; er wird hier bedeuten: "preiswürdig sein". Zu dem Mașdar hirajajt vgl. das nני bezw. חיז', das allein (nicht 'ypi! s. Lidzbarski, Eph. 2,106) zu רקי gestellt werden darf; also غالغالغ gesichert als Mașdar der Verba

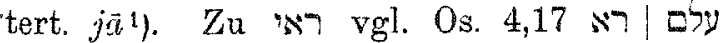
"das Zeichen, das er gesehen hat"; "sehen lassen" sc. ein Wahrzeichen; Os. 4 und unsere Inschrift gehören demselben Kreise an; es ist nicht ohne Bedeutung, dass beider Stifter unter dem Eindrueke von göttlichen Zeichen (על stehen ${ }^{2}$ ). - 12. בתחרב: da Os. 4,17 mit = der Ort des Sehens angegeben ist, erwartet man zunächst auch hier eine lokale Bestimmung; die dürfte aber in בר אaum zu finden sein; so wird $=$ hier Beziehungsausdruck sein: „über das ta-

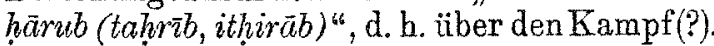

- 13. אה̄7: dabei wird es bleiben, so befremdlich es ist, da die Monatsnamen in der Regel mit $\overline{7}$ beginnen, S. OM S. 51; die Analogie verleitete zu der Annahme ad OM 12,13: "Vermutlich ist vorher [vor אज̄] ein $\mp$ ausgefallen". Unsere Inschrift gewährt einem 7 keinen Platz; so ist der רורה | רהתא gesichert als zweite Ausnahme neben ורור עבר

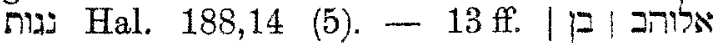

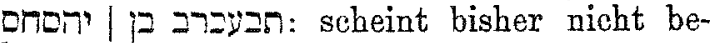
legt zu sein als Eponymus.

Uebersetzung: 1. Ilisa'd und sein Bruder Rijāb (Rabāb) 2. und seine Söhne 3. Ilī̌sarah und Ahșan und Abikarib, 4 aus der Sippe Bãqil, Diener 5. der Sippe Suchaim, weihten 6. ihrem Patron Ta'lab 7. Rijām, dem Herrn von Zabjān, 8. diese Statue, weil 9. er sie gehïtet hat durch seinen Sohutz, 10. und weil er sich preiswert gezeigt hat, indem er 11. sie ein Wahrzeichen schauen liess 12. über den Kampf im Monat 13. Dataa des

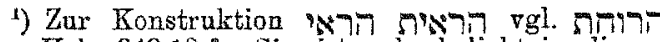
Th Hal. $349,10 \mathrm{f}$. Sie ist sehr beliebt in diesen Urkunden.

2) Os. 4,16 1. "wegen des Wahrzeichens, mit dem verseben wurde (gezeichnet wurde abyn) $\mathrm{Sa}$ dlăh, des Wahrzeichens, das er gesehen im Tempel des Ilmaqah"; auch in den qatabanischen Inschriften spielt das svo eine grosse Rolle: s. Gl. 1606,17. 23, und daza Gl. Altjem. Nacbr. 1,189. - Beachte die Schreibung $x$ Os. 4,17, wie auch Hal. 448,2(?), neben unserm inר: sie zeigt, dass die Aussprache $r a^{\prime} \bar{a}$, nicht $r a^{2} a j$ ( $\left.r a^{\prime} a i\right)$ war, nond dass man sich gelegentlich von der etymologischen Schreibart emanzipierte; in $\mathrm{N} \times \mathrm{T}$ ist an ihr festgehalten, obwohl man auch da gewiss har'a sprach (auch für $h i r^{2} \bar{a}$ wäre die Regel $x^{\prime}$ gอ gewesen).
Jahres des Iliwwahab 14. Ben Tubba'karib 15. Ben Juhashim, und weil er 16. sie wohl erhalten hat und wohl erhalten hat 17. ihr Gesinde und alles, 18. was sie erworben haben, und weil er 19. sie errettet hat von Uebel 20. und von Bedrückung und Schändlichkeit eines 21. Hassers und weil er sie beglitickt hat 22. mit seinem Wohlwollen und dem Wohlwollen 23. ihrer Herren, der Sippe Suchaim. 24. Bei Ta'lab Rijäm!

Ergebnisse: Die Inschrift Burchardt 3 ist unediert. Sie lehrt uns kennen: 1) eine neue Bauern-Sippe, die Banü Bāqil; 2) in ihr eine neue Pächterschaft der Banū Suchaim; 3) einen neuen Eponymus: Iliwahab Ben Tubba'karib Ben Juhashim; 4) "Herr von Zabjān" als Beinamen Ta'labs, das sich aus einem schon bekannten "in Zabjân" erschliessen liess, ist gesichert.

\section{Bespreehungen.}

K. Sethe, Urkunden der 18. Dynastie, 11. Heft. (Historisch-biographische Urkunden aus der Zeit Thutmosis III. Urk. des aegypt. Altertums IV, 11) 75 autogr. S. $4^{0}$. Leipzig (Hinrichs) 1907. $5 \mathrm{M}$. Besprochen von W. Max Müller.

Das ursprünglich nur für gewisse Schulzwecke angelegte Unternehmen nimmt mehr und mehr den Charakter eines Korpus an; es bringt hier unter anderem die bekannten grossen Listen eroberter Länder und Städte, stark den ursprünglichen Plan der "Urkunden" verlassend. Jedenfalls wäre es ein grosses Glück, wenn ein recht erschöpfendes Korpus erwachsen würde; die Zersplitterung des Inschriftenmateriales wird in der Aegyptologie von Jabr zu Jahr ein schlimmerer Uebelstand, durch zersplitterndes, plan- und sinnloses Wiederholen von Texten immer mehr vergrössert. Wer nicht einer sehr grossen öffentlichen Bibliothek nahe sitzt oder sehr reiche Mittel. zum Bücherkaufen hat, kann einfach nicht mehr mitkommen. Ich wiederhole nur meinen öfter geäusserten Wunsch: das vorliegende nützliche Unternehmen möge doch etwas mehr die Vergleichung der Originalausgaben überflüssig machen, um seinen Zweck ganz zu erfüllen; manchmal liesse sich mit ganz geringen Mitteln darin viel erzielen, z. B. durch Beibehaltung der ursprünglichen Schriftrichtung von oben nach unten wenigstens bei kleineren oder leicht abzuteilenden Texten (so z. B. bei den geographischen Listen) oder durch etwas weniger "Schlichtheit" beim Autographieren. 